\title{
PENGEMBANGAN MEDIA PEMBELAJARAN INTERAKTIF ONLINE MENGGUNAKAN EASYCLASS BERBANTUAN GEOGEBRA MATERI PROGRAM LINIER
}

\author{
Siti Mutrofin ${ }^{1}$, Susi Setiawani ${ }^{2}$, Saddam Hussen ${ }^{2}$ \\ Program Studi Pendidikan Matematika, FKIP, Universitas Jember \\ Jalan Kalimantan 37 Kampus Tegalboto Jember 68121 \\ E-mail: sitimutrofin47@gmail.com
}

\begin{abstract}
This development research produces online interactive learning media using GeoGebra-assisted linear programming Easyclass. The purpose of this study is to describe the process and results of developing interactive online learning media using GeoGebra-assisted Easyclass linear program material. Research using the 4-D Thiagarajan model. The study was conducted at MAN 2 Jember, followed by 24 students of class XI IPA 4. The results showed a correlation value of 0.917 so that the media was declared valid with a very high category. Practicality was analyzed based on a student response questionnaire showing a percentage of $99 \%$ so that it was declared practical with excellent criteria. The effectiveness was analyzed based on the test scores of student learning outcomes after using instructional media obtained a percentage of $88 \%$ of the number of students who scored more than 75 which were categorized very well. Based on the results of data analysis, online interactive learning media using Easyclassassisted GeoGebra linear program material meets the criteria of validity, practicality and effectiveness so that the media can be used in carrying out learning activities.
\end{abstract}

Keywords: Development, Easyclass, GeoGebra, Linear Programming

\section{PENDAHULUAN}

Matematika merupakan bidang studi yang menduduki peranan penting dalam bidang pendidikan [1]. Perkembangan era globalisasi memunculkan suatu isu revolusi industri keempat atau disebut revolusi industri 4.0 dimana salah satu inovasi dari revolusi 4.0 yaitu penggunaan media pembelajaran berbasis teknologi seperti media pembelajaran interaktif khususnya matematika [2]. Salah satu jenis media e-learning yang open source yaitu Easyclass. Easyclass adalah platform yang memungkinkan pendidik untuk membuat kelas online di mana mereka dapat

\footnotetext{
${ }^{1}$ Mahasiswa S-1 Prodi Pendidikan Matematika FKIP Universitas Jember

${ }^{2}$ Dosen Prodi Pendidikan Matematika FKIP Universitas Jember
} 
menyimpan materi kursus online; mengelola tugas, kuis dan ujian; memonitor tanggal jatuh tempo; nilai hasil dan memberikan umpan balik kesemua siswa di satu tempat. Easyclass diciptakan sebagai solusi yang mudah digunakan namun kuat yang akan menjadi standar baru untuk teknologi terbuka dalam pendidikan dan menjadikan pembelajaran lebih efisien [3]. Kelebihan Easyclass yaitu bisa mengirim pesan secara pribadi, terdapat upcoming events dengan menyisipkan batas waktu agar siswa mengetahui batas waktu tugas yang diberikan guru, tampilan lebih sederhana dan siswa menunggu persetujuan guru untuk masuk ke kelas khusus. Easyclass dimanfaatkan dan digunakan untuk mengembangkan kemampuan pendidikan dan keterampilan mengajar dan meningkatkan pendidikan siswa melalui penggunaan layanan dan teknik pendidikan yang tersedia di internet sehingga layanan platform pendidikan memungkinkan siswa belajar dari mana saja dan kapan saja [4].

Easyclass digunakan sebagai media untuk saling berdiskusi antara guru dengan siswa mengenai mata pelajaran yang memanfaatkan fitur discussions pada menu courses untuk mengidentifikasi efektivitas platform dalam Perguruan Tinggi yang ada di Irak [5]. Penelitian tersebut tidak memanfaatkan fitur-fitur lainnya seperti quizzes, gradebook, class wall, dsb. Agar Easyclass digunakan secara maksimal dan menambahkan kekurangan penelitian sebelumnya maka akan dilakukan penelitian dengan memanfaatkan fitur Easyclass yaitu quizzes untuk memasukkan kuis, discussion untuk berdiskusi dengan siswa dan class wall untuk memasukkan materi pembelajaran. Easyclass tidak menyediakan fitur untuk menggambar sebuah grafik sebagai alat penunjang konsep matematika, oleh karena itu dibutuhkan sebuah software yaitu GeoGebra yang dikemas praktis untuk mata pelajaran matematika. Menurut Syahbana GeoGebra merupakan program yang dapat mendemonstrasikan atau memvisualisasikan konsep-konsep matematika serta sebagai alat bantu untuk mengkonstruksikan konsep-konsep matematika [6]. GeoGebra dapat dijadikan sebuah software yang bersifat dinamis untuk membuat suatu konsep materi khususnya matematika. Pada GeoGebra tidak terdapat fitur berinteraksi antara siswa dengan guru [7]. GeoGebra dapat diakses secara online dan diunduh secara gratis melalui laman https://www.geogebra.org/. 
GeoGebra dijadikan sebagai salah satu software yang digunakan untuk materi program linier kelas XI [8] . Pemaparan diatas dapat dijadikan sebagai penelitian pengembangan dimana Easyclass digunakan sebagai media kelas online dan GeoGebra sebagai media visualisasi konsep dalam pembelajaran matematika khususnya materi program linier. Tujuan menggunakan kedua media ini untuk mendeskripsikan proses dan hasil pengembangan media pembelajaran interaktif online menggunakan Easyclass berbantuan GeoGebra materi program linier.

\section{METODE PENELITIAN}

Jenis penelitian ini adalah penelitian pengembangan (research and development). Model pengembangan yang digunakan yaitu model pengembangan 4-D Thiagarajan yang terdiri atas define, design, develop dan disseminate. Pelaksanaan uji coba penelitian di MAN 2 Jember. Subjek penelitian adalah siswa kelas XI IPA 4 yang diikuti 24 siswa. Instrumen penelitian ini yaitu pedoman wawancara, lembar validasi untuk menguji kevalidan media pembelajaran dan soal, tes belajar siswa dan angket respon siswa setelah menggunakan media pembelajaran. Media diuji berdasarkan tiga kriteria yaitu valid, praktis dan efektif. Media pembelajaran valid apabila memenuhi kategori tinggi yang mencapai nilai koefisien korelasi $>0,6$ dimana nilai koefisien korelasi didapat dari rata-rata nilai aspek dikali 0,25. Media pembelajaran praktis jika memenuhi kategori baik dengan persentase $>60 \%$ dimana persentase didapatkan dari nilai rata-rata indikator dikali 0,5. Media pembelajaran efektif jika rata-rata skor tes hasil belajar siswa memenuhi ketuntasan, yaitu $80 \%$ dari seluruh siswa mendapatkan skor lebih besar atau sama dengan Kriteria Ketuntasan Minimum (KKM) (KKM mata pelajaran matematika MAN 2 Jember adalah 75). Prosedur penelitian dapat dilihat pada Gambar 1. 


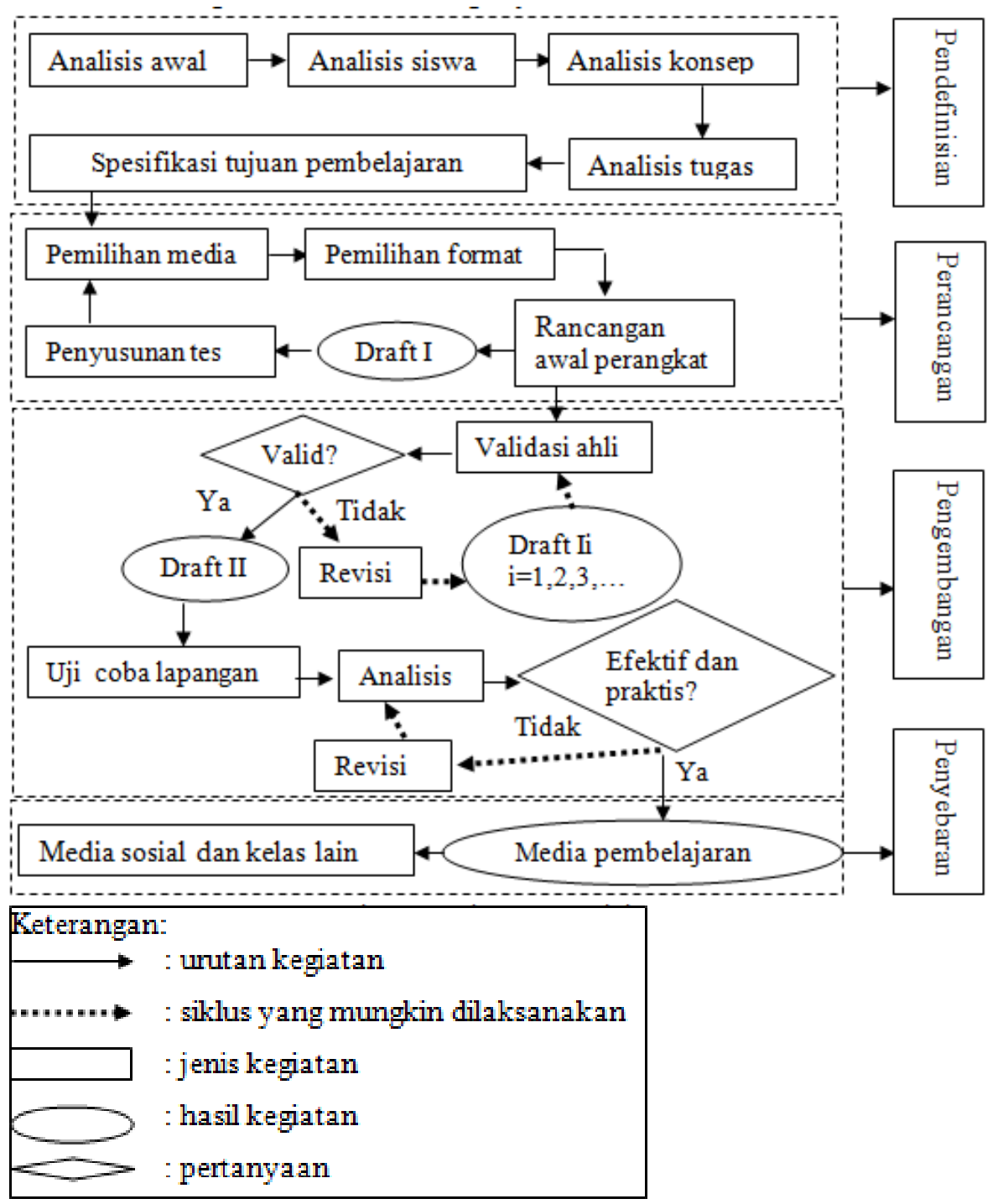

Gambar 1. Diagram 4-D Thiagarajan

\section{HASIL DAN PEMBAHASAN}

Penelitian ini mengembangkan media pembelajaran interaktif online berupa Easyclass berbantuan GeoGebra. Model pengembangan yang digunakan adalah model Thiagarajan yang terdiri dari empat tahapan, yaitu tahap pendefinisian (define), tahap perancangan (desaign), tahap pengembangan (develop) dan tahap penyebaran (disseminate).

\section{a. Tahap Pendefinisian (Define)}

Tujuan tahapan pendefinisian adalah mengembangkan media interaktif online menggunakan Easyclass berbantuan GeoGebra sebagai alat bantu dan 
sebagai media pembelajaran mandiri atau terbimbing untuk materi program linier kelas XI. Tujuan pembelajaran dapat ditentukan berdasarkan analisis awal-akhir, analisis siswa, analisis konsep, analisis tugas dan spesifikasi tujuan pembelajaran. Berdasarkan hasil wawancara bersama guru kelas XI IPA 4, pembelajaran matematika menggunakan media pembelajaran buku dari Kementerian Pendidikan dan Kebudayaan Republik Indonesia. Sistem penugasan dilakukan secara offline berbasis kertas sehingga software matematika seperti Mathlab, Maple, GeoGebra, Desmos dan sebagainya belum pernah digunakan sebagai pendukung media pembelajaran di kelas. Hal ini membuat siswa kurang bersemangat ketika proses pembelajaran berlangsung khususnya materi program linier. Maka dari itu dilakukan penelitian pengembangan menggunakan media pembelajaran online.

\section{b. Tahap Perancangan (Design)}

Pada tahap ini dilakukan perancangan media yaitu media pembelajaran Easyclass berbantuan GeoGebra. Tahap perancangan terdiri atas pemilihan media, pemilihan format, perancangan awal (design awal) media dan penyusunan tes pada media pembelajaran. media pembelajaran yang dikembangkan melalui laman www.easyclass.com kemudian disisipkan link GeoGebra sebagai media penunjang konsep materi. Penyusunan tes dan angket respon siswa setelah menggunakan media berada dalam Easyclass dengan memanfaatkan fitur yang telah tersedia. Perancangan media dapat dilihat pada Gambar 2.

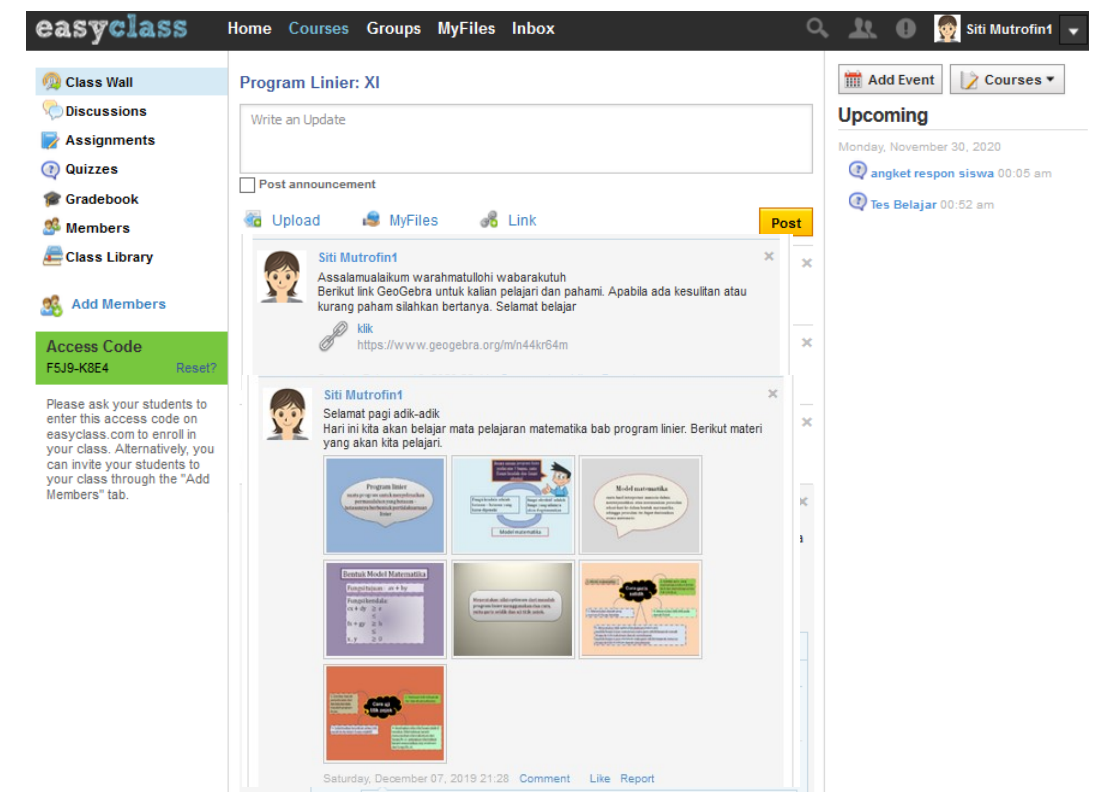


Gambar 2. Tampilan Utama Easyclass

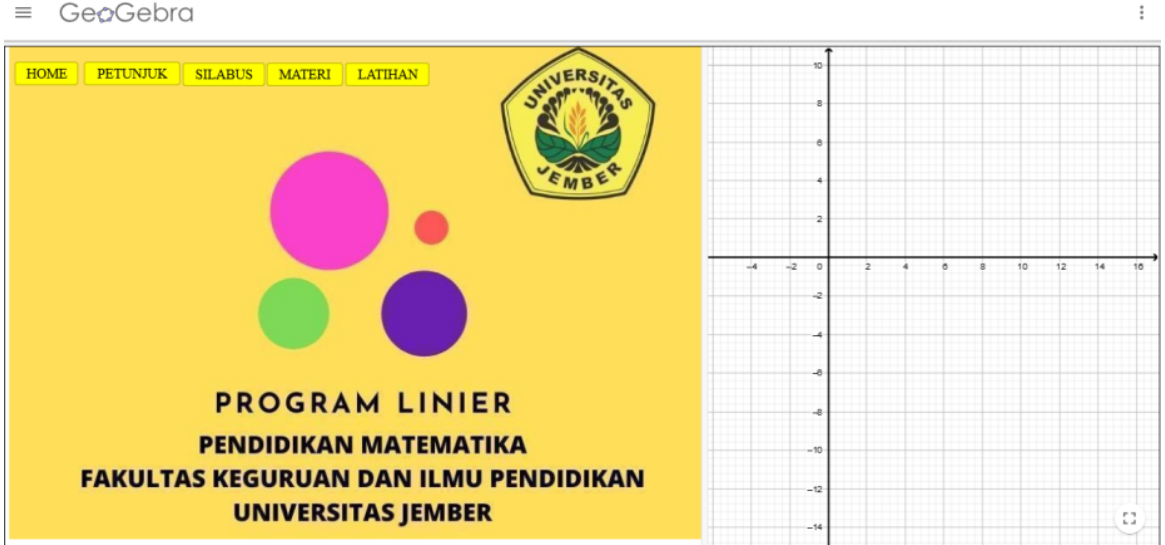

Gambar 3. Tampilan GeoGebra

\section{c. Tahap Pengembangan (Develop)}

Pada tahap ini menghasilkan draft I berupa GeoGebra yang telah diunggah dan ditautkan di Easyclass yang divalidasi oleh para ahli yang menghasilkan media pembelajaran yang telah direvisi berdasarkan masukan-masukan dari para ahli (draft II). Validator yang ditunjuk pada penelitian ini yaitu dua dosen pendidikan matematika Universitas Jember dan satu guru matematika kelas XI IPA 4 MAN 2 Jember. Para validator memberikan saran-saran sebagai bahan revisi agar menghasilkan media pembelajaran yang berkualitas dan layak di uji coba. Daftar validator dapat dilihat pada Tabel 4.1. Media dalam penelitian ini dapat dikatakan baik menurut [9] adalah kriteria kevalidan, kepraktisan, dan keefektifan.

Kriteria kevalidan media pembelajaran interaktif online menggunakan Easyclass berbantuan GeoGebra menunjukkan koefisien korelasi $(\propto)$ sebesar 0,917 dengan kategori "Sangat Tinggi" sehingga dapat dikatakan valid.Berikut grafik rata-rata aspek kevalidan. 


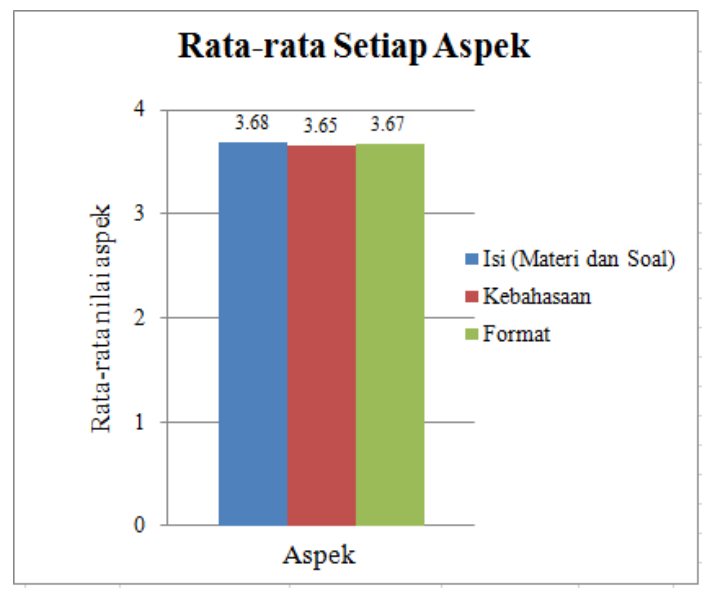

Gambar 4. Grafik Rata-rata Setiap Aspek Validasi

Setelah media pembelajaran dikatakan valid, selanjutnya dilakukan uji coba kepada siswa kelas XI IPA 4 di MAN 2 Jember untuk menganalisis kepraktisan, diperoleh persentase sebesar 99\% yang didapatkan dari pengisian angket respon pengguna setelah menggunakan media dengan kategori "Sangat Baik" sehingga media pembelajaran interaktif online menggunakan Easyclass berbantuan GeoGebra dikatakan praktis secara praktek. Media pembelajaran dikatakan praktis apabila media dapat digunakan dengan mudah dan menyenangkan serta dapat meningkatkan motivasi siswa untuk lebih semangat belajar. Hal ini selaras dengan penelitian yang mengungkapkan bahwa penggunaan media pembelajaran dapat meningkatkan motivasi siswa dalam belajar [10] sehingga membuat siswa lebih terkonsentrai pada materi yang dipelajari [8] serta kemunculan sebuah media dapat mempermudah siswa dalam memahami suatu konsep dan memberikan ilustrasi yang menarik bagi siswa [11]. 


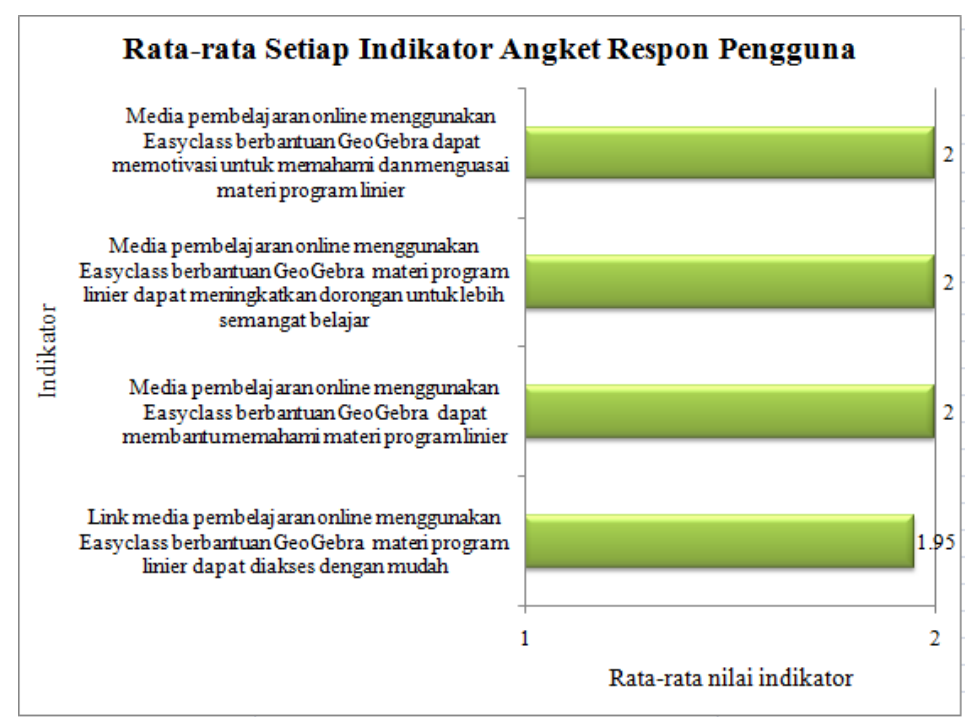

Gambar 5. Grafik Angket Respon Pengguna

Setelah siswa melakukan pengisian angket, selanjutnya dilakukan evaluasi setelah proses pembelajaran menggunakan media dapat dilihat pada Gambar 5.

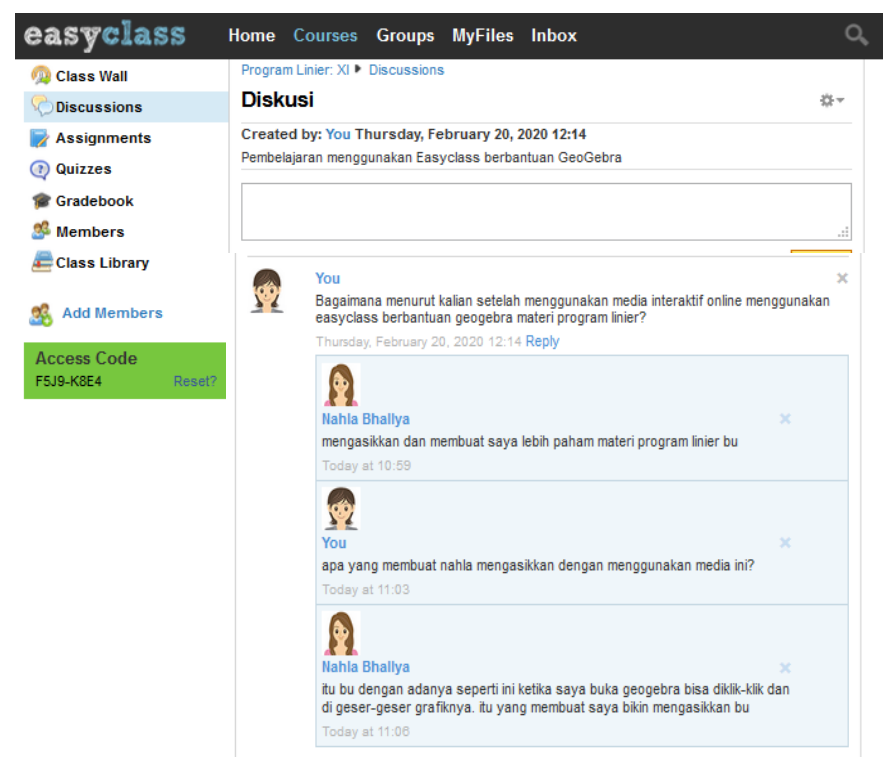




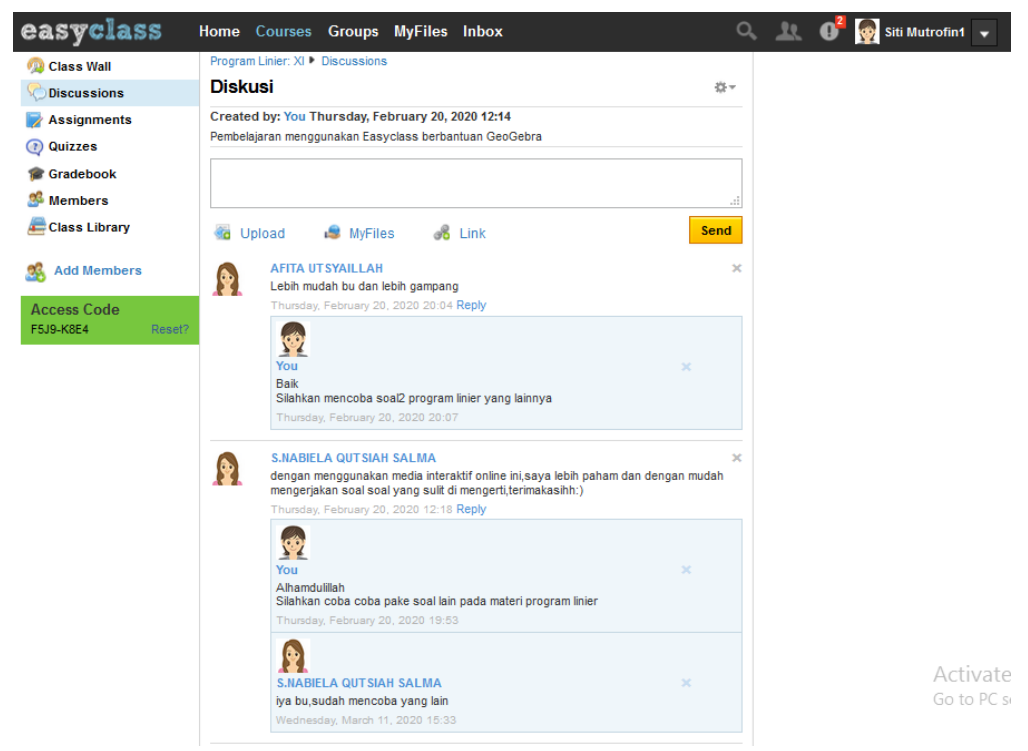

Gambar 6. Tampilan Interaktif

Kondisi saat pembuatan akun, kegiatan pembelajaran, dan mengerjakan tes berjalan dengan kondusif dan siswa memperhatikan ketika proses pembuatan akun sehingga tidak memerlukan waktu yang lama untuk membuat akun. Siswa merasakan keseruan saat menggunakan media pembelajaran Easyclass berbantuan GoGebra. Hal ini didukung oleh pendapat [12] bahwa media dapat meningkatkan keseruan dan pengalaman belajar dengan adanya saling berinteraksi.

Kriteria keefektifan didapat dari nilai siswa setelah mengerjakan tes hasil belajar yang diberikan. Media pembelajaran dikatakan efektif apabila nilai yang didapat siswa lebih dari atau sama dengan 75 (nilai KKM matematika MAN 2 Jember). Dalam penelitian ini, siswa yang mendapat nilai lebih dari atau sama dengan 75 sebanyak 21 siswa dari 24 siswa dengan persentase sebesar $88 \%$ dengan kategori "Sangat Baik". Penggunaan media online tidak hanya memperoleh ketuntasan nilai, tetapi juga meningkatkan hasil belajar siswa [13] dan media membawa dampak perubahan cara berkomunikasi dari konvensional menjadi modern dan serba digital yang menyebabkan komunikasi lebih efektif [14]. Dapat disimpulkan bahwa menggunakan media pembelajaran ini dapat meningkatkan hasil belajar siswa dibandingkan dengan pembelajaran secara tradisional. Berikut grafik nilai hasil belajar siswa. 


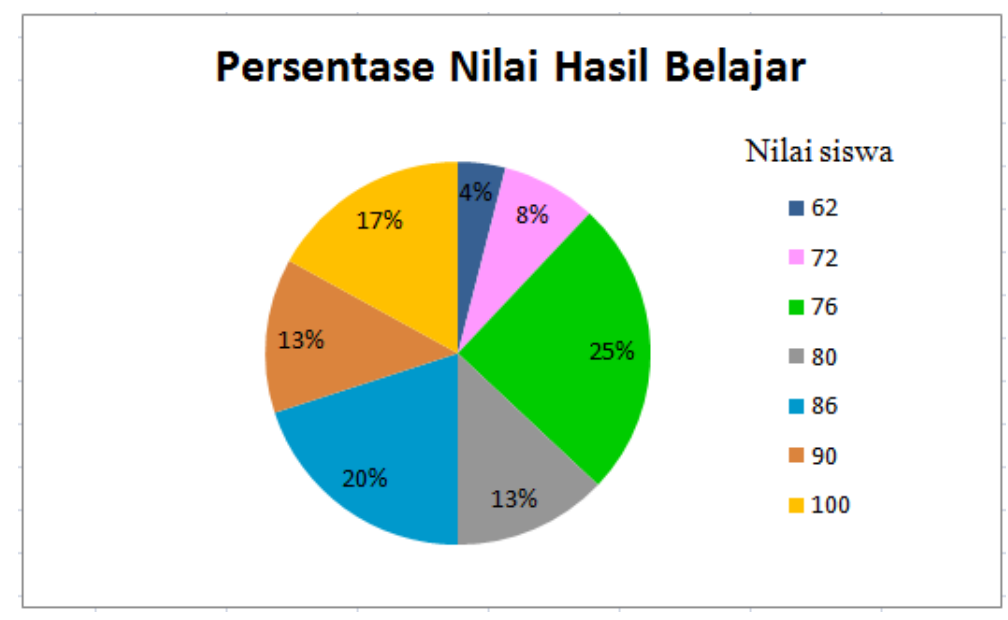

Gambar 7. Persentase Nilai Tes Hasil Belajar

Penelitian pengembangan media pembelajaran interaktif online menggunakan Easyclass berbantuan GeoGebra yang telah memenuhi ketiga kriteria yaitu valid, praktis dan efektif sehingga media pembelajaran interaktif online menggunakan Easyclass berbantuan GeoGebra siap digunakan sebagai media pembelajaran guru dalam melaksanakan pembelajaran.

\section{d. Tahap Penyebaran (Disseminate)}

Penyebaran dilakukan di tempat penelitian yaitu MAN 2 Jember dan selanjutnya melalui laman https://mediainterkatifonline.blogspot.com/2020/02/ pengembangan-media-pembelajaran.html

\section{KESIMPULAN}

Proses pengembangan media pembelajaran interaktif online menggunakan Easyclass berbantuan GeoGebra materi program linier melalui empat tahapan yaitu tahap pendefinisian, tahap perancangan, tahap pengembangan dan tahap penyebaran. Hasil pengembangan media pembelajaran interaktif online menggunakan Easyclass berbantuan GeoGebra materi program linier adalah 1) Valid diperoleh dari penilaian validator dengan nilai koefisien korelasi $\alpha$ sebesar 0,917 yang menujukkan kategori korelasi sangat tinggi. 2) Praktis berdasarkan angket respon siswa dengan nilai persentase sebesar 99\% yang menujukkan kategori sangat baik. 3) Efektif berdasarkan nilai tes hasil belajar siswa 
menunjukkan kategori sangat baik dengan persentase sebesar $88 \%$ dari banyaknya siswa yang memperoleh nilai $\geq 75$.

\section{DAFTAR PUSTAKA}

[1] U. A. Febriyanti, S. Setiawani, and Hobri, "Tingkat berpikir kreatif siswa kelas VII dalam menyelesaikan soal Open- Ended pada sub pokok bahasan persegi panjang dan persegi," Edukasi Unej, vol. 3, no. 2, pp. 5-8, 2016.

[2] R. P. Murtikusuma, A. Fatahillah, E. Oktavianingtyas, S. Hussen, and N. Lailiya, "The development of interactive mathematics learning media based on schoology and visual basic through industrial revolution 4.0 ," IOP Conf. Ser. Earth Environ. Sci., vol. 243, pp. 0-6, 2019.

[3] "Easyclass." [Online]. Available: https://www.easyclass.com/about. [Accessed: 14-Jul-2019].

[4] A. Chelghoum, "Promoting students' self-regulated learning through digital platforms : new horizon in educational psychology," Am. J. Appl. Psychol., vol. 6, no. 5, pp. 123-131, 2017.

[5] A. T. Jawad and C. H. Abboodi, "Use easyclass platform in higher education: University of Diyala college of basic education case," Int. J. Comput. Eng. Technol., vol. 9, no. 3, pp. 47-56, 2018.

[6] A. Hendrawan, Indriyani, and F. E. Anggraeni, "Perguruan Tinggi di Era Revolusi Industri 4.0," in Cilacap National Conference On Maritime And Multidisciplinary Study, 2018, p. 48.

[7] M. F. Fatoni, Dafik, and A. Fatahillah, "Pengembangan media pembelajaran interaktif online menggunakan KelasKita berbantuan software geogebra pada materi persamaan kuadrat," Kadikma, vol. 8, no. 2, pp. 24-33, 2017.

[8] B. Ariawan, "Menyelesaikan permasalahan program linier menggunakan GeoGebra," 2015.

[9] N. Nieveen, Design Approaches and Tools in Educational and Training. Dordrecht: Kluwer Academic Publisher, 1999.

[10] D. Setyadi and A. Qohar, "Pengembangan media pembelajaran matematika berbasis web pada materi barisan dan deret," Mat. Kreat., vol. 8, no. 1, pp. $1-7,2017$.

[11] B. Ariawan, G. Muhsetyo, and A. Qohar, "Analisis kebutuhan pengembangan multimedia pembelajaran berbasis edutainment materi program linier di SMK-PP N Kupang,” pp. 261-268, 2016.

[12] H. Mayatopani and N. Handayani, "Design implementasi kecerdasan buatan pada chatbot line dalam permainan tebak angka," JOUTICA, vol. 4, no. 1, pp. 226-231, 2019.

[13] Z. Ayvaz and S. Ozdemir, "Using GeoGebra as an Information Technology Tool : Parabola Teaching," Procedia - Soc. Behav. Sci., vol. 9, pp. 565572, 2010.

[14] A. Setiadi, "Pemanfaatan media sosial untuk efektifitas komunikasi," Humaniora, pp. 1-7, 2016. 